\title{
Article \\ Experimental Study on Mechanical Properties of Steel-Polyvinyl Alcohol Fibre-Reinforced Recycled Concrete
}

\author{
Haicheng Niu ${ }^{1}$, Lei Wang ${ }^{1, *}$, Jianhua $\mathrm{Li}^{2, *}$ (i) and Jiakun $\mathrm{Ji}^{1}$ \\ 1 School of Civil Engineering, Henan Polytechnic University, Jiaozuo 454000, China; \\ niuhch@hpu.edu.cn (H.N.); jiakun96@163.com (J.J.) \\ 2 College of Architectural Engineering, Huzhou Vocational and Technical College, Huzhou 313000, China \\ * Correspondence: 18530120958@163.com (L.W.); xjbnljh@126.com (J.L.); Tel.: +86-185-3012-0958 (L.W.); \\ +86-152-1095-4326 (J.L.)
}

Citation: Niu, H.; Wang, L.; Li, J.; Ji, J Experimental Study on Mechanical Properties of Steel-Polyvinyl Alcohol Fibre-Reinforced Recycled Concrete. Appl. Sci. 2021, 11, 10550. https:// doi.org/10.3390/app112210550

Academic Editor: Chao-Wei Tang

Received: 30 September 2021

Accepted: 29 October 2021

Published: 9 November 2021

Publisher's Note: MDPI stays neutral with regard to jurisdictional claims in published maps and institutional affiliations.

Copyright: (c) 2021 by the authors. Licensee MDPI, Basel, Switzerland. This article is an open access article distributed under the terms and conditions of the Creative Commons Attribution (CC BY) license (https:// creativecommons.org/licenses/by/ $4.0 /)$.

\begin{abstract}
Research on the utilization of recycled concrete in civil engineering applications is gaining popularity world-wide due to the increased efforts to promote preservation of the environment and sustainable development. Recycled concrete is, however, presently still limited to nonstructural applications. This is due to the poor mechanical properties of recycled concrete, which make it difficult to cope with complex mechanical environments. Therefore, an experimental work is presented to investigate the mechanical behaviour of recycled concrete, focusing on the cube, flexural, and uniaxial compressive mechanical properties of steel-polyvinyl alcohol fibre-doped specimens. The test results showed that the compressive strength and the flexural strength of the recycled concrete increased by $6.0 \%$ and $55.2 \%$, respectively, when steel fibre was single-incorporated. The cubic compressive strength of the recycled concrete decreased by $14.1 \%$ when polyvinyl alcohol fibre was single-incorporated, but there was a $47.9 \%$ increase in the flexural strength of recycled concrete. Based on these tests, the elastic modulus, the Poisson's ratio, and the uniaxial compression toughness were digitised to derive mathematical expressions that provided a theoretical understanding of the mechanical properties of steel-polyvinyl alcohol fibre-reinforced recycled concrete. Moreover, combining the characteristics of the uniaxial compressive stress-strain curve of fibre-reinforced recycled concrete, an equation for the uniaxial compressive stress-strain curve of recycled concrete associated with the fibre characteristic value was established, which agreed well with the test results.
\end{abstract}

Keywords: recycled concrete; steel fibre; polyvinyl alcohol fibre; fibre characteristic value; mechanical properties; stress-strain curve

\section{Introduction}

Hybrid fibre-reinforced concrete (HFRC) is a mixture of two or more fibres mixed into the concrete matrix to form a new composite material that can achieve different fibres to complement each other's strengths and advantages. At present, scholars at home and abroad have done research on the mechanical properties of HFRC, and the types of these fibres are steel fibre, polypropylene fibre, alkali-resistant glass fibre, basalt fibre, and polyvinyl alcohol fibre. For example, steel fibre has been used extensively in concrete in recent years. It was made by cutting fine steel wire or cold rolled strip shear with an aspect ratio of 40 to 80 . Basalt fibre is made from basalt stone molten at $1450-1500{ }^{\circ} \mathrm{C}$ and drawn at high speed through a platinum-rhodium alloy drawing funnel. It not only has high strength but also has a variety of excellent properties such as electrical insulation, corrosion resistance, and high temperature resistance. As a result, basalt fibre is widely used in many areas such as fibre-reinforced composites, shipbuilding materials, the automotive industry, and civil engineering. Alkali-resistant glass fibre is characterised by its effectiveness in resisting the high alkali substances in cement and its high tensile and flexural strength, and it therefore also belongs to a green reinforcing material used in high-performance reinforced concrete. Polypropylene fibre and polyvinyl alcohol fibre have the advantages of high 
strength, toughness, chemical resistance, and microbial resistance, so it is commonly used as fibre additive in concrete. Banthia [1], Qian [2], and Li [3] mixed steel and polypropylene fibre into concrete in different proportions to carry out mechanical properties tests, and the results showed that mixing different fibres into concrete could significantly improve the compressive and flexural strengths. Mehran [4] mixed steel fibre, polypropylene fibre, and glass fibre into concrete and carried out a semicircular bending test (SCB), which showed that the hybrid fibre enhanced the ductility and load-bearing capacity of the concrete, with the glass fibre enhancing the ductility of the concrete and the steel fibre improving the energy absorption capacity of the concrete. Vishaul [5] chose to mix alkali-resistant glass fibre and coconut bark fibre into concrete to study the effect of hybrid fibre on the mechanical properties of concrete, and the test results showed that hybrid fibre can enhance the compressive strength and tensile strength of concrete; the impact resistance had also improved. Based on the above research, it has been shown that HFRC has incomparable advantages over single-fibre-reinforced concrete, and it improves the mechanical properties of concrete in many aspects and multiple dimensions.

In recent years, the acceleration of urbanization in various countries has brought about the impact that many dilapidated residential buildings have been demolished, resulting in a large amount of construction waste, which is extremely detrimental to environmental protection. However, research has shown that recycled coarse aggregate obtained by crushing waste concrete from construction waste can replace natural coarse aggregates in the preparation of recycled aggregate concrete (RAC), and the application and development of recycled concrete technology is an important measure to realise the resourcefulness of construction waste and to ensure the sustainable development of construction resources [6]. Existing research results show that the compressive strength and splitting tensile strength of recycled concrete decrease as the replacement ratio of recycled coarse aggregate increases $[7,8]$. The shape of the uniaxial compressive stressstrain curve of recycled concrete is basically similar to that of natural concrete, but the peak stress and elastic modulus decrease significantly as the replacement rate of recycled coarse aggregate increases $[9,10]$. As the old mortar bonded to the surface of the recycled coarse aggregate causes an increase in aggregate water absorption and a decrease in adhesion to the cement matrix, the mechanical properties of RAC are significantly reduced compared to natural aggregate concrete $[11,12]$. Therefore, the lack of mechanical properties is the major constraint on the use of recycled concrete in civil engineering.

To improve the strength and toughness of recycled concrete, researchers have incorporated fibre into recycled concrete to enhance its mechanical properties. Steel fibre incorporated into recycled concrete resulted in an increase in the compressive strength of the matrix $[13,14]$ and a substantial improvement in flexural toughness [15-17]. Polyvinyl alcohol fibre is a polymeric synthetic material, and the hydrophilic properties of their surface improve the bonding force with the cement matrix [18]. The compressive strength and splitting tensile strength of the concrete were increased to varying degrees when polyvinyl alcohol fibre was incorporated [19].

It can be seen that the incorporation of fibre in recycled concrete is an effective method to improve the strength, cracking resistance, and toughness of recycled concrete [20,21]. Based on this, this study incorporated steel fibre and polyvinyl alcohol fibre into highstrength recycled concrete to study the effects of different fibre types, mixing amounts, and mixing methods on the compressive strength and flexural strength of high-strength recycled concrete, and it also evaluated the uniaxial compressive properties of steel-polyvinyl alcohol fibre-reinforced recycled concrete in terms of the elastic modulus, the Poisson's ratio, and the uniaxial compression toughness index. Based on the stress-strain curve equation proposed in the literature [22], the stress-strain curve was fitted to the measured stress-strain curve by using the fibre characteristic value as the variation factor, and the fitted curve was in good agreement with the test results, which can provide a theoretical basis for the structural design of hybrid fibre-reinforced recycled concrete. 


\section{Materials and Methods}

\subsection{Raw Materials}

P•O42.5-grade cement was produced by a normal cement factory. Fly ash and S95 blast furnace granulated slag were produced by a power plant with specific gravities of 2.18 and 2.89, respectively. Quartz sand with a particle size distribution in the range of $0.05-0.50 \mathrm{~mm}$ was used as fine aggregate with a fineness modulus of 2.78 . Natural coarse aggregate (NCA) was crushed stone and recycled coarse aggregate (RCA) from the demolition of pavement slab on San Yang Road, Jiaozuo, and it was crushed and screened by the Shenghe Building Materials Plant before being obtained. After investigation, the strength of the original waste pavement concrete was $\mathrm{C} 25$. The physical properties of the natural and recycled coarse aggregate are shown in Table 1. According to the Chinese National Standard GB/T25177-2010 [23], the water absorption rate of category I recycled coarse aggregate is less than $3 \%$; the water absorption rate of category II recycled coarse aggregate is among $3-5 \%$; the water absorption rate of category III recycled coarse aggregate is among $5-8 \%$; and the water absorption rate of recycled coarse aggregate used in this study is $6.3 \%$, so it belongs to category III recycled coarse aggregate. The grading curves of the aggregates (sand, NCA, and NRC) are shown in Figure 1. The superplasticizer is a polycarboxylic acid water reducing agent, allowing for water reduction of up to $30 \%$ to achieve the target workability. The mixing water was tap water from Jiaozuo, China.

Table 1. Physical indicators related to the coarse aggregate.

\begin{tabular}{cccccc}
\hline $\begin{array}{c}\text { Coarse } \\
\text { Aggregate }\end{array}$ & Grain Size (mm) & $\begin{array}{c}\text { Moisture } \\
\text { Content (\%) }\end{array}$ & $\begin{array}{c}\text { Water } \\
\text { Absorption (\%) }\end{array}$ & $\begin{array}{c}\text { Apparent } \\
\text { Density (kg/m } \mathbf{~}^{3} \text { ) }\end{array}$ & $\begin{array}{c}\text { Crushing } \\
\text { Index (\%) }\end{array}$ \\
\hline NCA & $5-25$ & 1.0 & 0.93 & 2798 & 10.4 \\
RCA & $5-25$ & 2.2 & 6.30 & 2433 & 12.7 \\
\hline
\end{tabular}

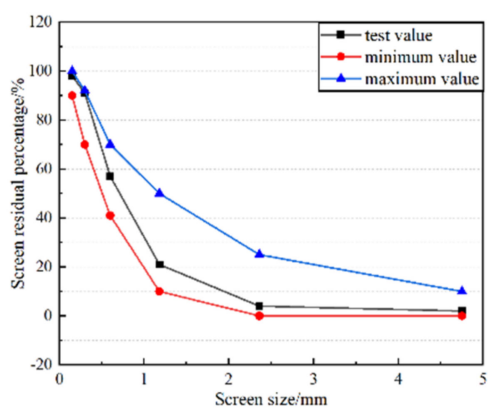

(a) Sand

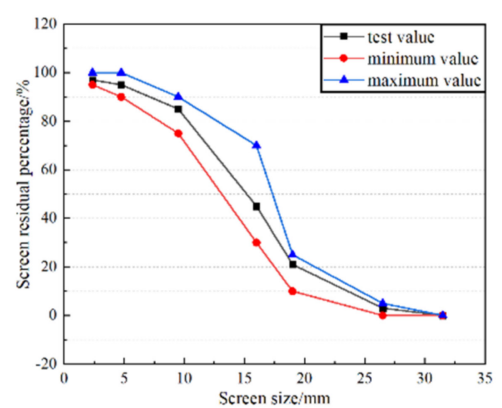

(b) NCA

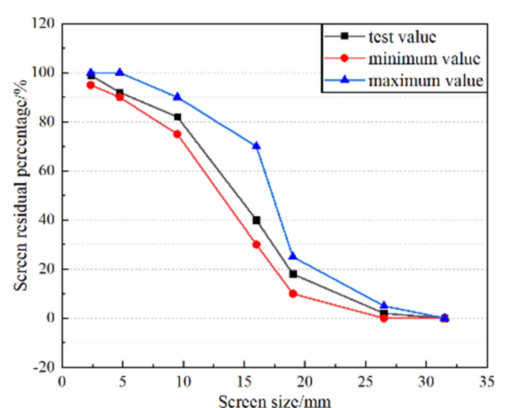

(c) RCA

Figure 1. The grading curves of the aggregate.

Steel fibre (SF) was produced by the Hengshui Yongming fibre manufacturing plant with a density of $7.8 \mathrm{~g} / \mathrm{cm}^{3}$, while the diameter and length were $0.6 \mathrm{~mm}$ and $37 \mathrm{~mm}$, respectively; the ultimate tensile strength was not less than $1060 \mathrm{MPa}$. Polyvinyl alcohol fibre (PVA-F) was produced by the Changzhou Tianyi Engineering fibre manufacturing plant with a density of $1.27 \mathrm{~g} / \mathrm{cm}^{3}$, while the length was $19 \mathrm{~mm}$, the diameter was $15 \mu \mathrm{m}$, and the ultimate tensile strength was not less than $1500 \mathrm{MPa}$. The appearance of the SF and PVA-F are shown in Figure 2. 


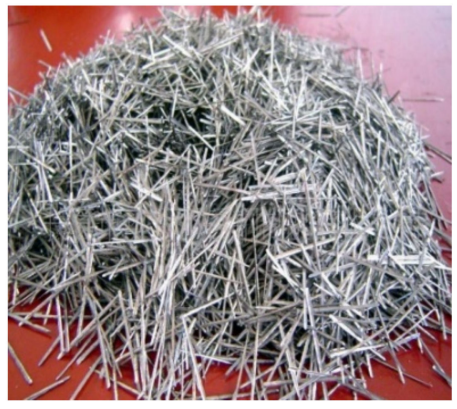

(a) $\mathrm{SF}$

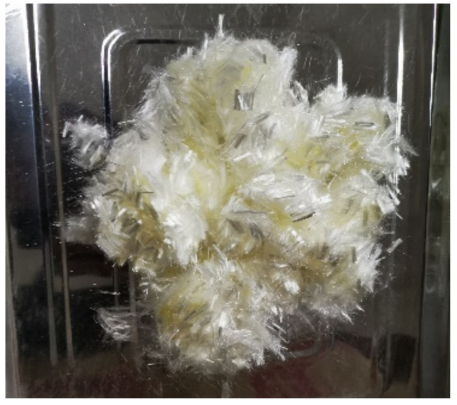

(b) PVA-F

Figure 2. Types of fibre.

\subsection{Specimen Design}

The test was divided into 11 groups, and the fibre admixture and recycled coarse aggregate replacement rate $\gamma$ for each test group are shown in Table 2. The number of specimens in each test type was three. Fly ash and S95 blast-furnace-granulated slag were selected as mineral admixtures to partially replace cement. The standard group of concrete (NC) was prepared from natural coarse aggregate; the reference group of concrete (RC) was prepared from recycled coarse aggregate; and, due to the higher water absorption of recycled coarse aggregate, the additional mixing water of recycled concrete was determined to be $5 \mathrm{~kg} / \mathrm{m}^{3}$. The concrete mix proportions are listed in Table 3 .

Table 2. Test grouping.

\begin{tabular}{|c|c|c|c|c|}
\hline \multirow{2}{*}{ Specimen } & \multirow{2}{*}{ Fibre Length (mm) } & \multicolumn{2}{|c|}{ Volume Percentage (\%) } & \multirow{2}{*}{$\begin{array}{c}\text { Recycled Coarse } \\
\text { Aggregate Replacement Rate } \gamma\end{array}$} \\
\hline & & SF & PVA-F & \\
\hline $\mathrm{NC}$ & - & - & - & $(\%)$ \\
\hline $\mathrm{RC}$ & - & - & - & 100 \\
\hline RS-1 & 37 & 0.5 & - & 100 \\
\hline RS-2 & 37 & 1.0 & - & 100 \\
\hline RS-3 & 37 & 1.5 & - & 100 \\
\hline RP-1 & 19 & - & 0.1 & 100 \\
\hline RP-2 & 19 & - & 0.2 & 100 \\
\hline RP-3 & 19 & - & 0.3 & 100 \\
\hline RSP-1 & $37 / 19$ & 0.5 & 0.3 & 100 \\
\hline RSP-2 & $37 / 19$ & 1.0 & 0.2 & 100 \\
\hline RSP-3 & $37 / 19$ & 1.5 & 0.1 & 100 \\
\hline
\end{tabular}

Table 3. Concrete sample mixtures for experiments $\left(\mathrm{kg} / \mathrm{m}^{3}\right)$.

\begin{tabular}{ccccccccr}
\hline Specimens & Cement & Fly Ash & S95 & Water & Sand & NCA & RCA & $\begin{array}{r}\text { Water } \\
\text { Reducer }\end{array}$ \\
\hline NC & 336.80 & 48.13 & 96.25 & 154.00 & 633.50 & 1126.15 & 0 & 2.41 \\
RC & 336.80 & 48.13 & 96.25 & 159.00 & 633.50 & 0 & 1126.15 & 2.41 \\
\hline
\end{tabular}

\subsection{Test Methodology}

The concrete specimen preparation process is shown in Figure 3. According to Chinese standard test methods for mechanical properties of concrete [24], with the dimensions of the cubic compressive strength specimen being $150 \mathrm{~mm} \times 150 \mathrm{~mm} \times 150 \mathrm{~mm}$, the flexural strength specimen was $150 \mathrm{~mm} \times 150 \mathrm{~mm} \times 550 \mathrm{~mm}$, and the uniaxial compression specimen was $150 \mathrm{~mm} \times 150 \mathrm{~mm} \times 300 \mathrm{~mm}$. 


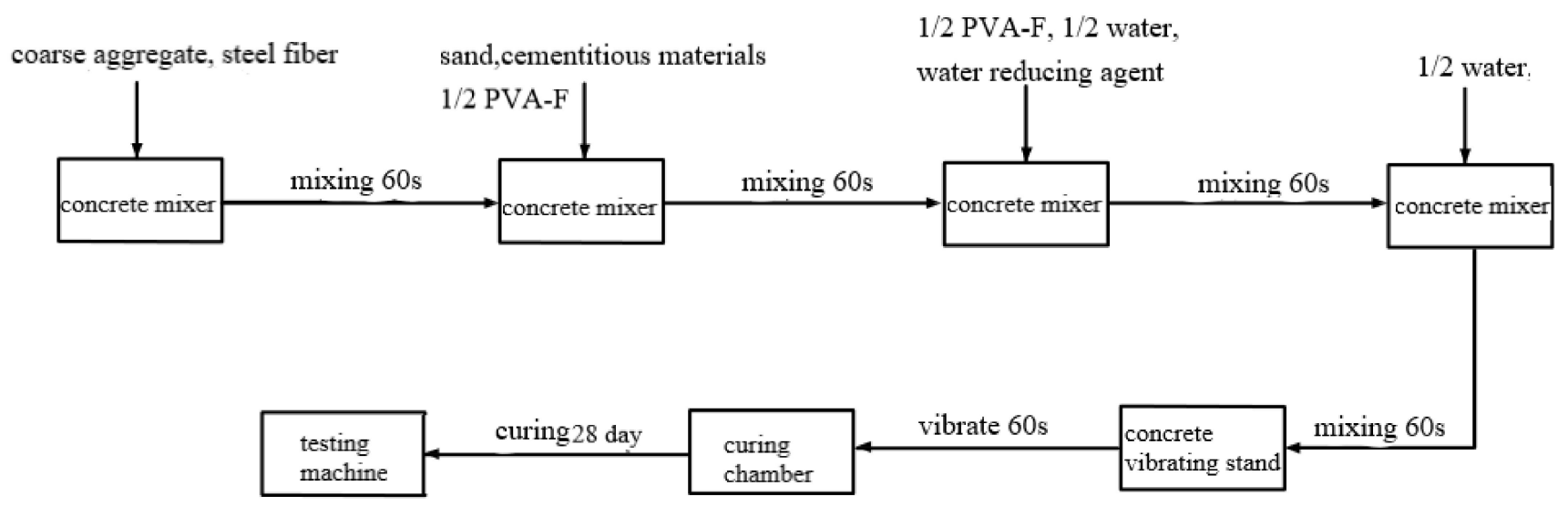

Figure 3. Preparation process of specimens.

The mixing and curing for specimens were as follows: the concrete mixer was rinsed clean before mixing and pre-mixed with a small amount of the same concrete mix proportions. During the mixing process, concrete was mixed for more than 1 min until it was evenly mixed. The test mould was attached to the vibration table, then vibration continued until the surface of the slurry and until there was no obvious large bubble overflow. After vibration, the specimen was placed in a room with a temperature of $20^{\circ} \mathrm{C} \pm 5{ }^{\circ} \mathrm{C}$ and a relative humidity of more than $50 \%$ for $1 \mathrm{~d}$. After demoulding, the specimens were immediately put into a standard maintenance room with a temperature of $20^{\circ} \mathrm{C} \pm 2{ }^{\circ} \mathrm{C}$ and a relative humidity of $95 \%$ or more, and the test specimens were maintained for 28 days. The specimens' mixing and curing process is shown in Figure 4.

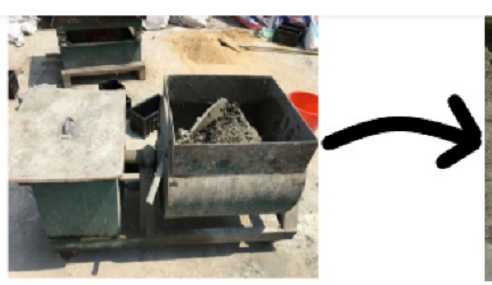

Process 1

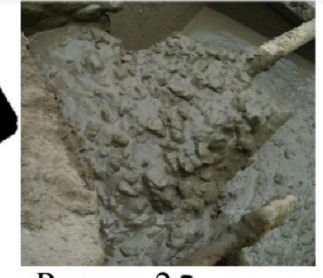

Process 2

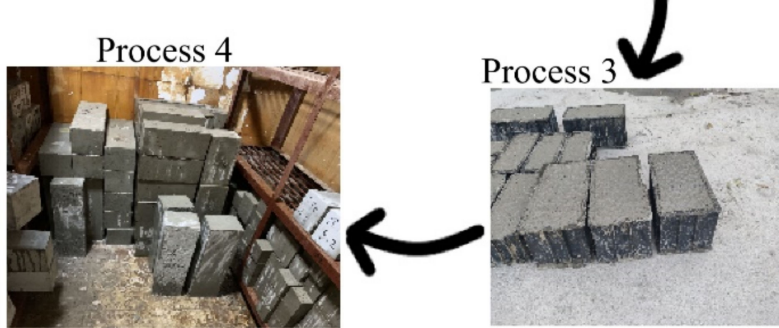

Figure 4. The mixing and curing process of specimens.

The uniaxial compression test was loaded in a displacement control, and the whole loading rate was $0.2 \mathrm{~mm} / \mathrm{min}$. The displacement was measured using an LVDT displacement gauge, which was positioned in the middle of the specimen using a deformation measuring frame and bolts, with a measuring distance of $150 \mathrm{~mm}$. The load was measured by using the sensor of the electro-hydraulic servo universal testing machine, then the uniaxial compression stress-strain curve was plotted according to the measurement results. The test loading device is shown in Figure 5. 


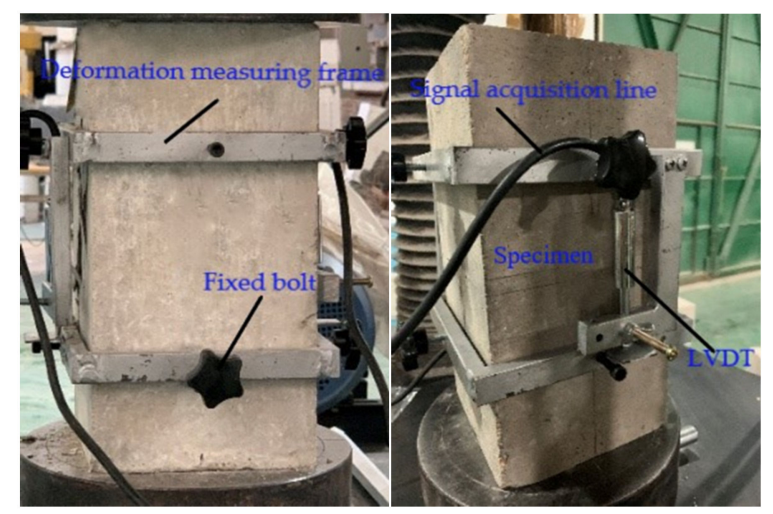

Figure 5. The device of uniaxial compression test.

\subsubsection{Elastic Modulus and Poisson's Ratio}

The test was carried out according to the "Static compressive elastic modulus test" and "Poisson's ratio test" as specified in the Chinese National Standard GB/T50081-2019 [25], with a load control method and a rate of $10 \mathrm{kN} / \mathrm{s}$. The loading process is shown in Figure 6. The elastic modulus was calculated according to Equations (1) and (2), and Poisson's ratio was calculated according to Equation (3).

$$
\begin{gathered}
E_{\mathrm{c}}=\frac{F_{\mathrm{a}}-F_{0}}{A} \times \frac{L}{\Delta n} \\
\Delta n=\varepsilon_{a}-\varepsilon_{0} \\
\mu=\frac{\varepsilon_{t a}-\varepsilon_{t 0}}{\varepsilon_{a}-\varepsilon_{0}}
\end{gathered}
$$

where $E_{\mathrm{c}}$ : elastic modulus of concrete in static compression (MPa); $F_{\mathrm{a}}$ : load at $1 / 3$ uniaxial compressive strength $(\mathrm{N}) ; F_{0}$ : initial load at $0.5 \mathrm{MPa}$ uniaxial compressive strength $(\mathrm{N})$; $A$ : compression area of the specimen $\left(\mathrm{mm}^{2}\right) ; L$ : measurement distance of specimen $(\mathrm{mm})$; $\Delta n$ : average value of deformation on both sides of the specimen at the last loading from $F_{0}$ to $F_{\mathrm{a}}(\mathrm{mm}) ; \varepsilon_{a}$ : average value of deformation on both sides of the specimen at $F_{\mathrm{a}}$ $(\mathrm{mm}) ; \varepsilon_{0}$ : average value of the deformation on both sides of the specimen at $F_{0}(\mathrm{~mm})$; $\mu$ : Poisson's ratio of concrete (the calculation result should be accurate to 0.01 ); $\varepsilon_{t a}$ : average value of transverse strains on both sides of the specimen at the last $F_{\mathrm{a}}(\mathrm{mm}) ; \varepsilon_{t 0}$ : average value of transverse strains on both sides of the specimen at the last $F_{0}(\mathrm{~mm})$.

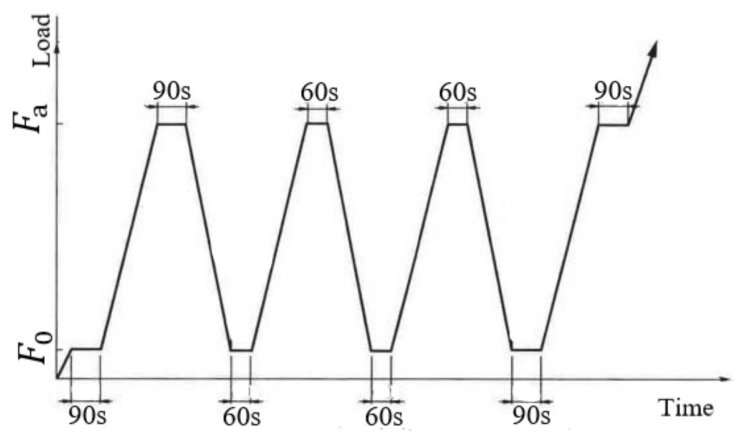

Figure 6. The loading process of sample.

\subsubsection{Uniaxial Compression Toughness Index}

Concrete toughness is generally defined as the performance of a concrete material in absorbing energy when damage occurs under load. To facilitate the characterisation of concrete uniaxial compression toughness, the toughness index (TI) was introduced [26]. 
In uniaxial compression tests, a schematic diagram of the calculation of the uniaxial compression toughness index is shown in Figure 7.

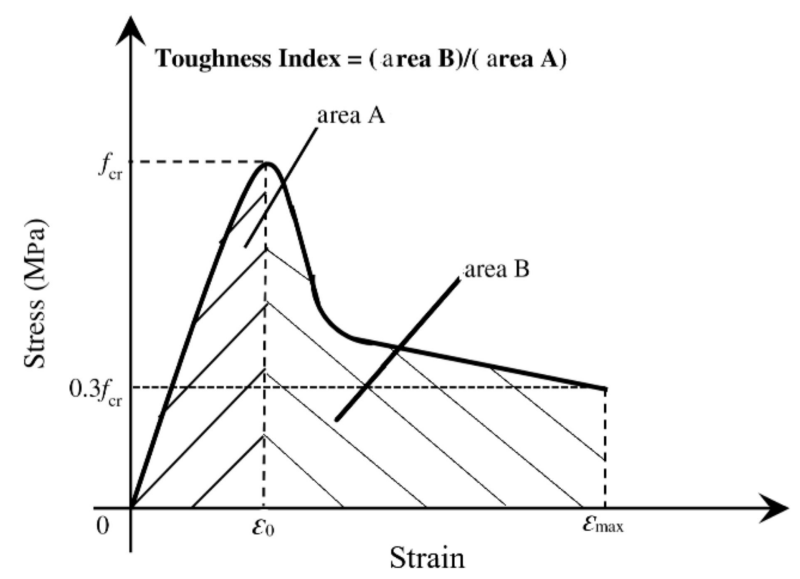

Figure 7. The calculation of uniaxial compression toughness index.

\section{Results and Discussion}

The test results include the concrete slump, the cubic compressive strength $f_{\mathrm{cc}}$, the flexural strength $f_{\mathrm{f}}$, the uniaxial compressive strength $f_{\mathrm{c}}$ and its peak strain $\varepsilon_{\mathrm{c}}$, the elastic modulus $E_{\mathrm{c}}$, the Poisson's ratio $v_{t}$, and the uniaxial compressive toughness index TI. The characteristic values of steel fibre $\lambda_{\text {sf }}$ and polyvinyl alcohol fibre $\lambda_{\text {pf }}$ were calculated according to Equations (4) and (5).

$$
\begin{aligned}
& \lambda_{\mathrm{sf}}=V_{\mathrm{sf}} l_{\mathrm{sf}} / d_{\mathrm{sf}} \\
& \lambda_{\mathrm{pf}}=V_{\mathrm{pf}} l_{\mathrm{pf}} / d_{\mathrm{pf}}
\end{aligned}
$$

where $V_{\mathrm{sf}}$ and $V_{\mathrm{pf}}$ are the volume dosing of steel fibre and polyvinyl alcohol fibre, respectively; $l_{\mathrm{sf}} / d_{\mathrm{sf}}$ is the steel fibre aspect ratio; and $l_{\mathrm{pf}} / d_{\mathrm{pf}}$ is the polyvinyl alcohol fibre aspect ratio.

\subsection{Specimen Failure Mode}

Figure 8 shows the compressive damage patterns of the RC, PVA-F, and SF recycled concrete cube specimens, respectively. During the compression of the RC specimens, the concrete cube on the surface gradually spalled off and made a "cracking" sound during the destruction process, which was typical of brittle damage as shown in Figure 8a. After the recycled concrete was mixed with polyvinyl alcohol fibre, the surface of the PVA-F specimen was intact during the damage, no spalling occurred, and only a few wide cracks were generated at the corners of the specimen as shown in Figure 8b. The main reason for this was that the uniform distributed polyvinyl alcohol fibre in the concrete matrix effectively reduced the stress concentration at the crack tip. When the recycled concrete was mixed with steel fibre, the cube specimens showed a "cracked" damage pattern, with the pieces still bonded to each other at the cracks and with only a few spalling off as shown in Figure 8c. 


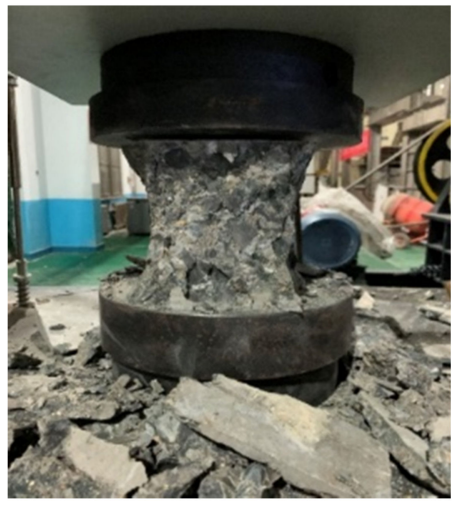

(a) $\mathrm{RC}$

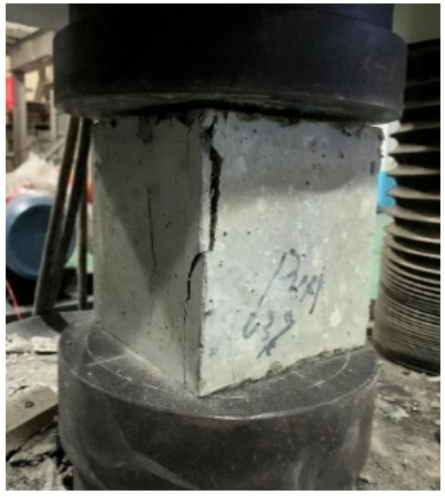

(b) PVA-F

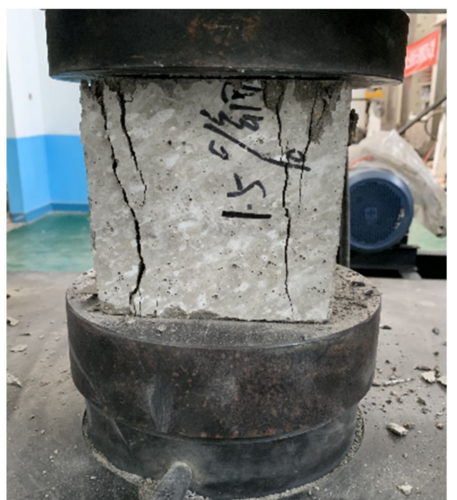

(c) SF

Figure 8. Failure patterns of test cube concrete.

The flexural damage patterns of the RC, PVA-F, and SF recycled concrete specimens are shown in Figure 9. During the flexural test, the RC and PVA-F recycled concrete specimens fractured immediately after loading to the peak load, showing typical brittle damage as shown in Figure 9a,b. The SF recycled concrete specimens could hear the "thump" sound of the steel fibre being broken off during the loading process, and the cracks from the tensile area of the specimens gradually extended upwards with a tortuous path; the deformation of the specimens became larger and larger, showing a "cracked but continuous load-bearing" damage pattern. Figure $9 \mathrm{c}-\mathrm{e}$ shows the damage pattern of SF specimens with $0.5 \%, 1.0 \%$, and $1.5 \%$ of steel fibre volume content, respectively, from left to right.

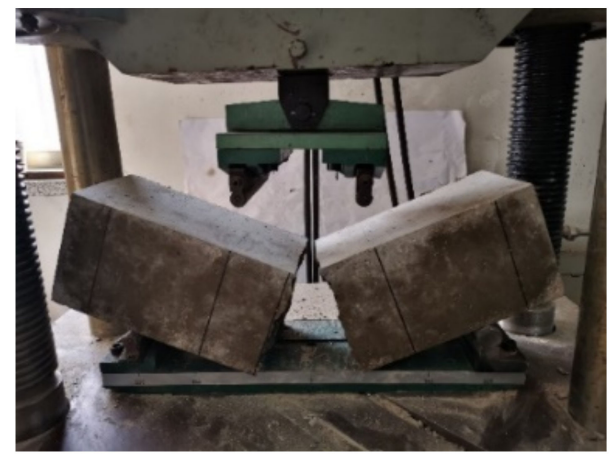

(a) RC

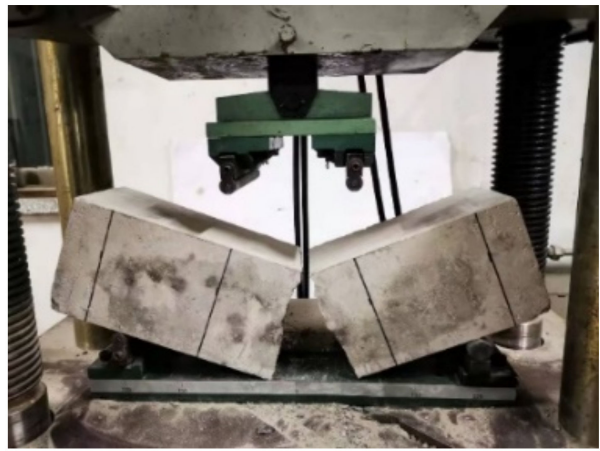

(b) PVA-F

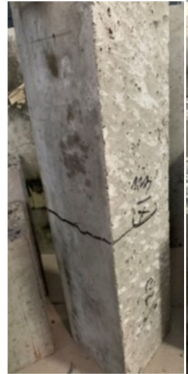

(c) $0.5 \%$

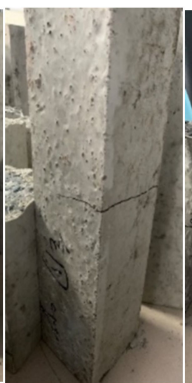

(d) $1.0 \%$

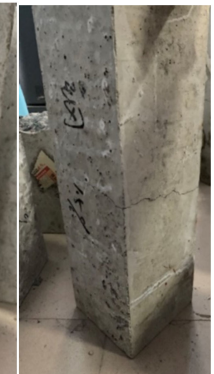

(e) $1.5 \%$

Figure 9. Failure patterns of flexural specimens.

\subsection{Cube Compressive Strength}

The cube compressive strength of SF, PVA-F, and hybrid fibre (HF) recycled concrete with different fibre volume admixtures are shown in Figure 10, where the RC compressive strength was $66.4 \mathrm{MPa}$. From Figure 10a, it can be seen that with the increase in the volume admixture of steel fibre, the overall compressive strength of recycled concrete showed an 
increasing trend, and when the volume admixture amount was in the range of $0.5 \%$ to $1.0 \%$, the compressive strength was increased to a greater extent. The compressive strength increased by $6.0 \%$ compared to RC when the volume admixture of steel fibre was $1.5 \%$. That indicates that steel fibre can improve the compressive strength of recycled concrete. That is because when initial cracks appeared in the specimens, the bond between the steel fibre and the matrix prevented the cracks from developing rapidly. At the same time, the steel fibre across the crack and near the crack tip transferred the stress to the concrete matrix on the upper and lower surfaces of the crack, relieving the degree of stress concentration at the crack tip.

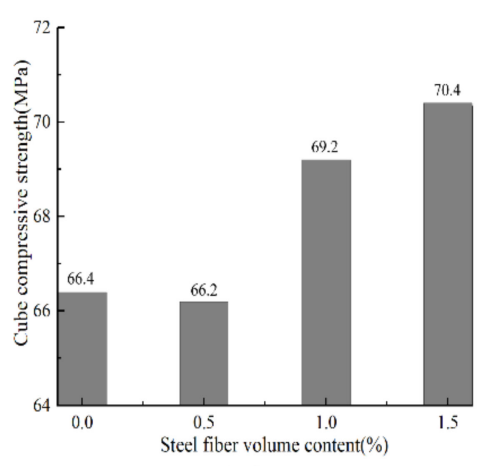

(a) $\mathrm{SF}$

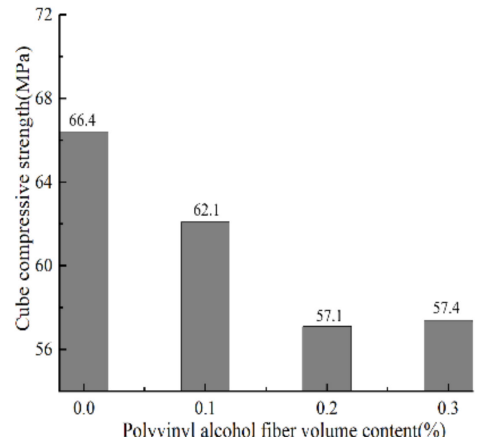

(b) PVA-F

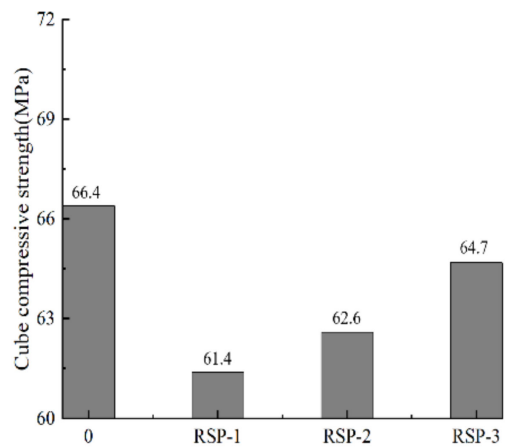

(c) $\mathrm{HF}$

Figure 10. Cube compressive strength of fibre-reinforced recycled concrete.

As can be seen from Figure 10b, with the increase in the volume admixture of polyvinyl alcohol fibre, the overall compressive strength of the recycled concrete tended to decrease. When the volume admixture of polyvinyl alcohol fibre was $0.2 \%$, the compressive strength decreased by $14.1 \%$ compared to RC, and thereafter, the compressive strength was basically unchanged. As the polyvinyl alcohol fibre mixed into concrete, it produced a certain airentraining effect, leading to an increase in porosity between the cementitious material and the aggregates. Therefore, as the volume admixture of polyvinyl alcohol fibre increased, the encapsulation of the cementitious material gradually weakened, resulting in a large number of micro-cracks during compression; thus, the compressive strength of the recycled concrete was weakened.

Figure 10c shows the compressive strength of the hybrid fibre (HF) recycled concrete, where the RSP-1 specimen had the lowest compressive strength. The possible reasons for this are that the excessive incorporation of PVA fibre resulted in the fibre not being sufficiently encapsulated by the cement slurry, thus increasing internal defects of concrete, which is not conducive to compression, and the limited increase in compressive strength due to the low amount incorporation of steel fibre. The increase in compressive strength of the RSP-2 and RSP-3 specimens compared to the RSP-1 specimen was mainly due to the increase in the incorporation amount of steel fibre, which effectively restrained and prevented the expansion of cracks. The compressive strength of all three groups of hybrid fibre specimens was below RC. It can be inferred that the increase of compressive strength by steel fibre was not sufficient to offset the weakening of PVA fibre.

\subsection{Flexure Strength}

The flexural strengths of the recycled concrete with SF, PVA-F, and HF are shown in Figure 11, where the RC flexural strength was 4.87 MPa. From Figure 11a, it can be seen that the flexural strength of the recycled concrete showed an increasing trend followed by a decreasing trend. The highest flexural strength was achieved when the steel fibre volume dosing was $1.0 \%$, with an increase of $55.2 \%$ compared to RC. The main reason for this is that, when the steel fibre content is low, the fibres are evenly dispersed in the concrete, and the fibre and concrete are subjected to common forces and coordinated deformation. As the volume content of steel fibre increased, the steel fibre in sheets 
effectively controlled the development of micro-cracks and energy absorption, so that the concrete can continue to carry the load despite cracking. Thus, the flexural strength of recycled concrete was enhanced. However, when the steel fibre was mixed in excessive quantities, the phenomenon of steel fibre agglomeration occurred during the concrete preparation and mixing process. Thus, the flexural strength was reduced.

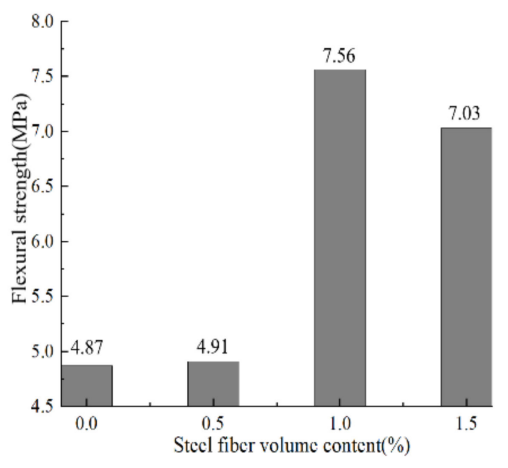

(a) SF

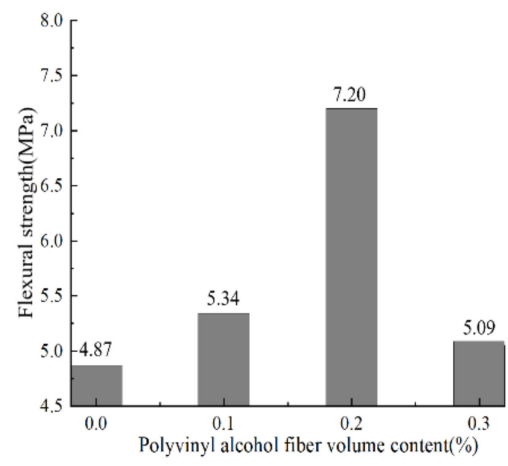

(b) PVA-F

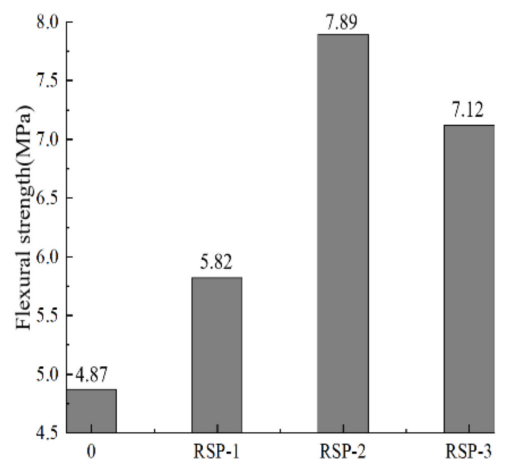

(c) $\mathrm{HF}$

Figure 11. Flexural strength of fibre-reinforced recycled concrete.

As can be seen from Figure $11 \mathrm{~b}$, the flexural strength was optimum at $0.2 \%$ by volume of polyvinyl alcohol fibre and increased by $47.9 \%$ compared to RC. As the volume amount of polyvinyl alcohol fibre was increased, the flexural strength of the recycled concrete first increased and then decreased significantly. The possible reasons for this are that the reasonable amount of polyvinyl alcohol fibre can be dispersed evenly within the concrete matrix to fill the voids, reducing the possibility of generating through cracks, but the excessive amount of polyvinyl alcohol fibre absorbs a significant amount of water during the concrete mixing process and forms bundles of fibre that are difficult to disperse, increasing the interface weakness of the concrete. Thus, the flexural strength was reduced.

The flexural strength of hybrid fibre recycled concrete is shown in Figure 11c. Comparing the three groups of hybrid specimens (RSP-1, RSP-2, and RSP-3), it can be seen that RSP-2 had the highest flexural strength, indicating that the mixing of PVA-F and SF at the same time in the optimal amount of the single admixture was conducive to realize a win-win situation, together limiting the development of microcracks so that the flexural performance was significantly enhanced.

\subsection{Stress-Strain Curve}

Figure 12 shows the uniaxial compressive stress-strain curves for recycled concrete and natural concrete. The uniaxial compressive stress-strain curves of the RC specimen were significantly lower in both uniaxial compressive strength and slope compared to the NC specimen, as shown in Figure 12. The main reason for this is that the old mortar adhering to the surface of the recycled coarse aggregate affects the adhesion between the aggregate and the cement matrix, resulting in more weak interfaces within the recycled concrete, and therefore the uniaxial compressive strength and elastic modulus of the recycled concrete were significantly reduced. 


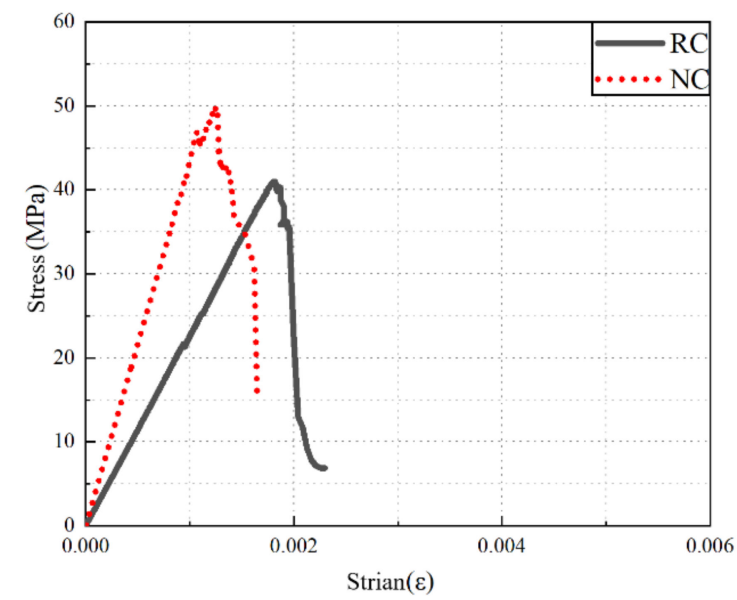

Figure 12. Uniaxial compression stress-strain curve of recycled concrete and natural concrete.

The uniaxial stress-strain curve for single admixture fibre recycled concrete is shown in Figure 13. The uniaxial compressive strength of SF recycled concrete increased with the increase in fibre admixture and increased by up to $14.2 \%$ compared with that of non-fibre recycled concrete. The softening branch tends to flatten out. The main reason is that the steel fibre volume amount increased. On the one hand, the number of steel fibre involved in restraining concrete cracking increased, while, on the other hand, steel fibre absorbed more of the concrete's compression deformation energy, which was converted into their own tensile deformation energy. So, the softening branch of the uniaxial stress-strain curve for recycled concrete became smoother, as shown in Figure 13a.

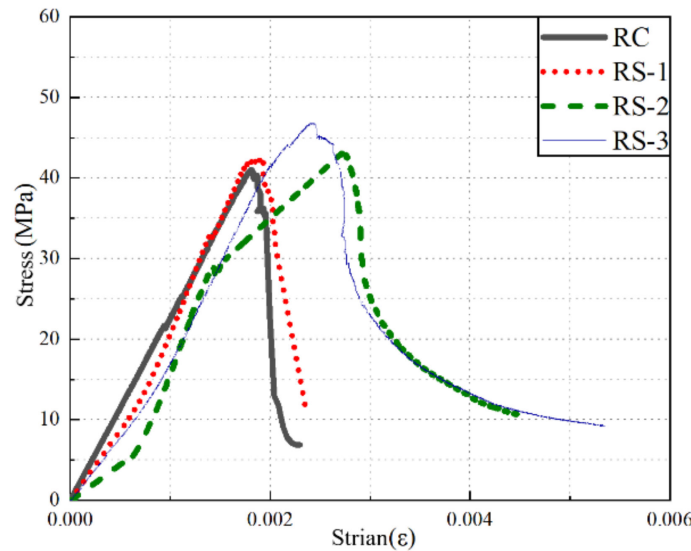

(a) SF

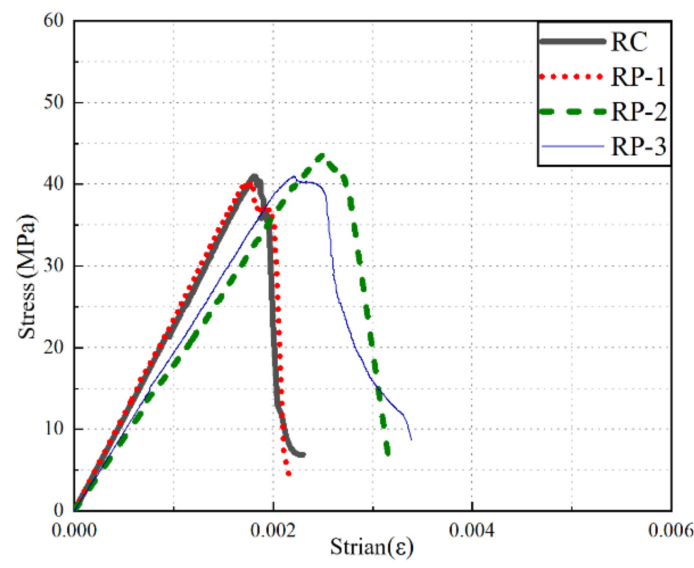

(b) PVA-F

Figure 13. Uniaxial compression stress-strain curve of recycled concrete with single fibre mixture.

As can be seen from Figure 13b, the difference between the RP-1 stress-strain curve and the RC was not significant, indicating that a small amount of polyvinyl alcohol fibre admixture had a small effect on the uniaxial compressive stress-strain behaviour of the recycled concrete. Comparing the curves of RP-1, RP-2, and RP-3, it can be seen that as the volume admixture of polyvinyl alcohol fibre increased, the uniaxial compressive strength and the peak strain first increased and then decreased, and the softening branch of the stress-strain curve tended to flatten from a steep drop. This indicates that the deformation capacity and the energy absorption capacity of the specimens increased during the stresssoftening stage. The reason for this is that more polyvinyl alcohol fibre was used to link the cracked surfaces of the recycled concrete, improving the bond of the cracked surface of concrete. Thus, more energy was required to deform the specimen by cracking. 
The uniaxial compressive stress-strain curve for both single and hybrid fibre recycled concrete is shown in Figure 14. The uniaxial compressive stress-strain curve for the RSP-1 specimen has a similar shape to the RP-3 specimen, but the falling section of the RSP-1 specimen stress-strain curve is more smoothness, as shown in Figure 14a. The reason for this is that the RSP-1 specimen not only had a larger amount of polyvinyl alcohol fibre, but it also had a small amount of steel fibre compared to RP-3, and these steel fibres further shared the load on the fracture surface of the specimen. Therefore, the RSP-1 specimen had an increased capacity to dissipate energy during the compressive damage period, which is reflected in a smoother falling section of the stress-strain curve.

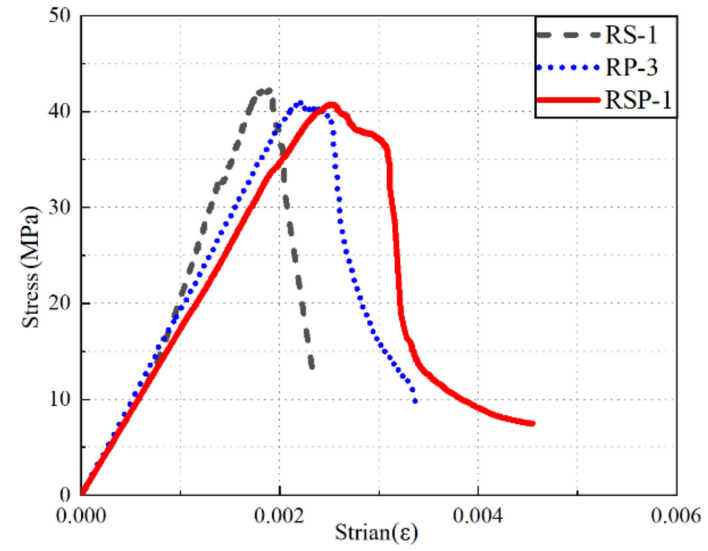

(a) RSP-1

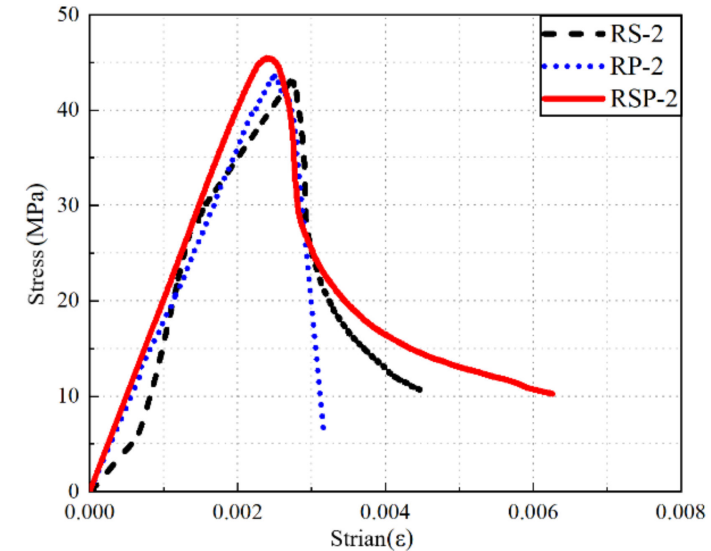

(b) RSP-2

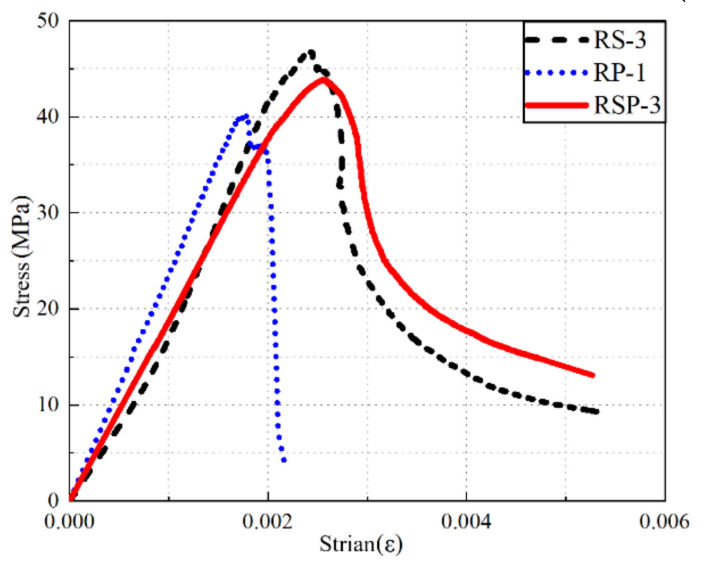

(c) RSP-3

Figure 14. Uniaxial compressive stress-strain curve of single and hybrid recycled concrete.

The uniaxial compressive stress-strain curve for the hybrid fibre recycled concrete RSP-2 specimen showed an increase in the slope of the rising section of the curve compared to both RS-2 and RP-2, and a smoother softening branch, as shown in Figure 14b. The possible reason for this is that the mixing of polyvinyl alcohol fibre and steel fibre produced a synergistic effect compared to the single-fibre recycled concrete, with the double fibre contributing to each other and together enhancing the compressive strength, the elastic modulus, and the deformation properties of the recycled concrete.

The shape of the stress-strain curve of the hybrid fibre recycled concrete RSP-3 specimen was more similar to that of RS-3, but the softening branch of the RSP-3 specimen had greater smoothness, and the residual strength increased, as shown in Figure 14c. The reason for this is that, compared to RS-3, RSP-3 specimens contained a small amount of polyvinyl alcohol fibre, which effectively linked the micro-cracked surface of the recycled concrete and reduced the possibility of the micro-cracked surface expanding into a macrocracked surface so that specimen RSP-3 had an increased resistance to cracking during the 
compressive damage period, which made it easier for the recycled concrete to deform in a coordinated manner as a whole.

\subsection{Quantitative Analysis of Test Results}

The test results are shown in Table 4.

Table 4. The test results of fibre recycled concrete.

\begin{tabular}{ccccccccc}
\hline Specimen & Slump $(\mathbf{m m})$ & $\lambda_{s f}$ & $\lambda_{p f}$ & $E_{\mathbf{c}}(\mathbf{M P a})$ & $v_{t}$ & $f_{\mathbf{c}}(\mathbf{M P a})$ & $\varepsilon_{\boldsymbol{c}}\left(10^{6}\right)$ & $\mathbf{T I}$ \\
\hline NC & 201 & 0 & 0 & 40,818 & 0.229 & 49.87 & 1254 & 0.4383 \\
RC & 176 & 0 & 0 & 22,746 & 0.220 & 40.99 & 1802 & 0.2113 \\
RS-1 & 161 & 0.308 & 0 & 18,603 & 0.204 & 42.29 & 1915 & 0.2938 \\
RS-2 & 149 & 0.617 & 0 & 14,871 & 0.182 & 43.05 & 2726 & 0.4524 \\
RS-3 & 132 & 0.925 & 0 & 15,316 & 0.195 & 46.80 & 2420 & 0.6475 \\
RP-1 & 150 & 0 & 1.26 & 24,074 & 0.219 & 40.11 & 1787 & 0.2652 \\
RP-2 & 131 & 0 & 2.53 & 18,449 & 0.201 & 43.59 & 2510 & 0.3291 \\
RP-3 & 112 & 0 & 3.8 & 20,866 & 0.187 & 40.98 & 2210 & 0.5801 \\
RSP-1 & 75 & 0.308 & 3.8 & 16,979 & 0.179 & 40.76 & 2501 & 0.5662 \\
RSP-2 & 94 & 0.617 & 2.53 & 18,571 & 0.187 & 45.48 & 2391 & 0.9481 \\
RSP-3 & 110 & 0.925 & 1.26 & 15,990 & 0.177 & 43.88 & 2557 & 0.9618 \\
\hline
\end{tabular}

\subsubsection{Elastic Modulus}

As can be seen from Table 4, the elastic modulus of recycled concrete decreased when steel fibre and polyvinyl alcohol fibre were incorporated. The reason for this is that the air-entraining effect of the polyvinyl alcohol fibre increased the porosity of the recycled concrete and therefore reduced the elastic modulus of the recycled concrete, while the larger size of the steel fibre, which requires more cement paste to be wrapped, reduced the compactness of the matrix and created more interfacial weak zones within the concrete, which reduced the elastic modulus.

Based on the elastic modulus equation presented in [27], a non-linear regression analysis was carried out with the experimental results to obtain the elastic modulus of steel-polyvinyl alcohol fibre recycled concrete as a function of the fibre characteristic values and the uniaxial compressive strength, as shown in Figure 15. In Figure 15, the red dots are the spatial coordinate points corresponding to the elastic modulus, the fibre characteristic value, and the uniaxial compressive strength of the test samples, and the spatial surface was obtained from the regression analysis of the test points. These points were more evenly distributed on the top and bottom sides of the spatial surface. As the fibre characteristic value increased, the elastic modulus of the recycled concrete gradually decreased.

$$
E_{\mathrm{c}}=\frac{10^{5}}{2.2+97.54 / f_{\mathrm{c}}}\left(1-0.365 \lambda_{\mathrm{sf}}\right)\left(1-0.020 \lambda_{\mathrm{pf}}\right)
$$

\subsubsection{Poisson's Ratio}

Poisson's ratio is an important indicator of the transverse deformation of concrete. Equation (7) can be obtained by a non-linear regression analysis of the measured results. Figure 16 shows the relationship of the Poisson's ratio and the fibre characteristic value. It can be seen that the Poisson's ratio specimen points had a slightly larger dispersion from the non-linear regression equation, but the Poisson's ratio of recycled concrete decreased with the fibre characteristic value increase. 


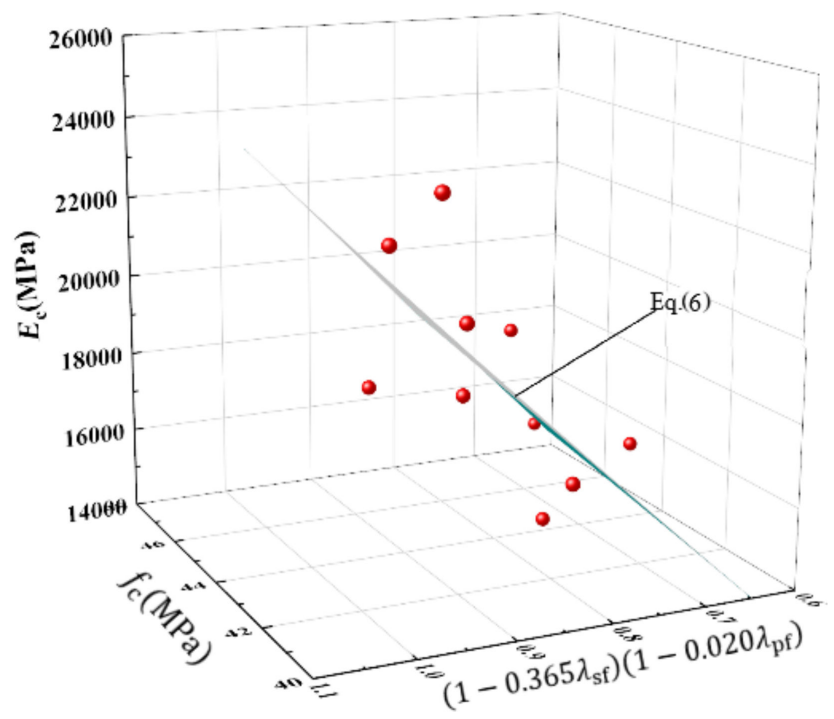

Figure 15. The function of fibre characteristic value, elastic modulus, and uniaxial compression strength.

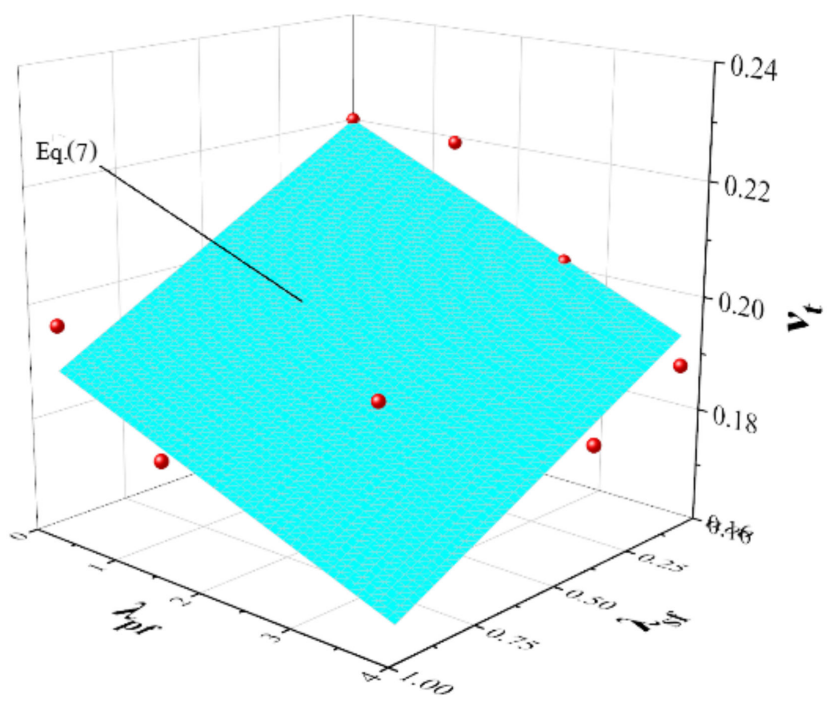

Figure 16. Fibre characteristic value and Poisson's ratio.

As can be seen from Equation (7) and Table 4, the Poisson's ratio was reduced when steel fibre and polyvinyl alcohol fibre were incorporated into recycled concrete. The reason for this is that the bond and friction between the steel fibre or polyvinyl alcohol fibre and the cement matrix restrained the lateral deformation of the recycled concrete specimens during the compression of the concrete, thus the Poisson's ratio was reduced.

$$
v_{t}=0.994 v_{0}\left(1-0.162 \lambda_{\mathrm{sf}}\right)\left(1-0.033 \lambda_{\mathrm{pf}}\right)
$$

where, $v_{0}$ is the Poisson's ratio of non-fibre recycled concrete.

\subsubsection{Uniaxial Compressive Toughness}

As can be seen from Table 4, the uniaxial compressive toughness of RC was reduced by $51.8 \%$ compared to NC. The uniaxial compressive toughness of recycled concrete increased with the increase in the volume content of steel and polyvinyl alcohol fibre, with the uniaxial compressive toughness of recycled concrete increasing by $39.04-206.43 \%$, compared to RC. When $1.0 \%$ steel fibre by volume and $0.2 \%$ polyvinyl alcohol fibre by 
volume were hybrid, the uniaxial compressive toughness increased by $109.57 \%$ and $188.08 \%$ compared to steel fibre or the polyvinyl alcohol fibre single admixture. Thus, this mixing plan is a superior combination for improving uniaxial compressive toughness of recycled concrete. The non-linear regression analysis was used to obtain Equation (8). Figure 17 shows the relationship of fibre characteristic values, peak strain, ultimate strain, and the uniaxial compression toughness index. The test points were less discrete from the spatial curve, while the uniaxial compressive toughness increased with the increase in the fibre characteristic value, and the larger the ratio of ultimate strain to peak strain of the concrete specimen, the higher the uniaxial compressive toughness, as shown in Figure 17.

$$
\mathrm{TI}=0.208\left(\frac{\varepsilon_{\mathrm{max}}}{\varepsilon_{0}}\right)^{1.762}\left(1+0.22 \lambda_{\mathrm{sf}}\right)\left(1+0.08 \lambda_{\mathrm{pf}}\right)
$$

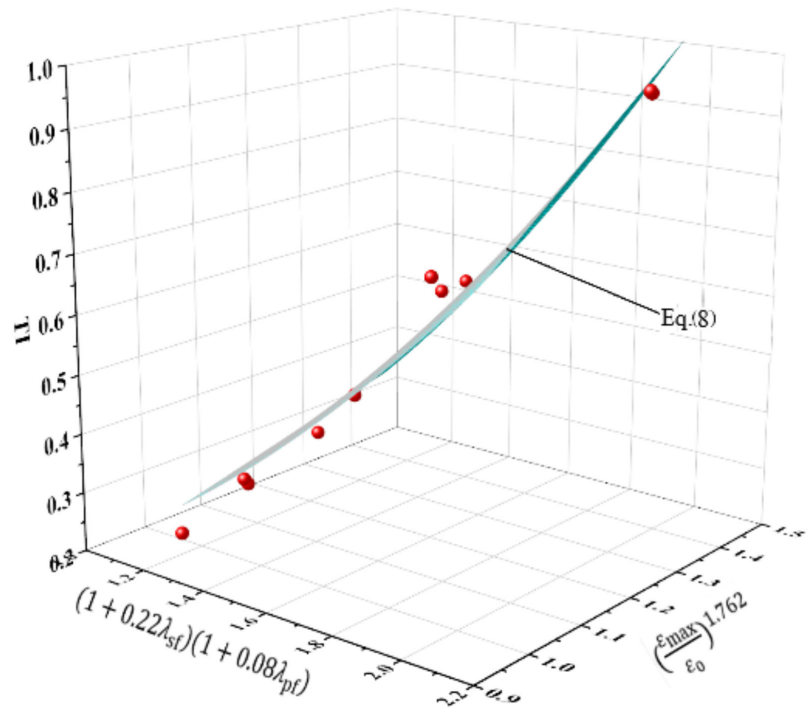

Figure 17. The relationship of fibre characteristic value, peak strain, ultimate strain, and uniaxial compression toughness index.

Equation (8) shows that both steel fibre and polyvinyl alcohol fibre can improve the uniaxial compressive toughness of recycled concrete, and steel fibre was more effective in improving the uniaxial compressive toughness of recycled concrete compared to polyvinyl alcohol fibre. The elastic modulus, the Poisson's ratio, and the uniaxial compression toughness index calculated by Equations (6)-(8) were compared with the measured values in Table 5.

Table 5. The relative error between the calculated value and the measured value.

\begin{tabular}{|c|c|c|c|c|c|c|c|c|c|}
\hline \multirow[b]{2}{*}{ Specimen } & \multicolumn{2}{|c|}{$E_{\mathrm{c}}(\mathrm{GPa})$} & \multirow[b]{2}{*}{$\begin{array}{l}\text { Relative } \\
\text { Error (\%) }\end{array}$} & \multicolumn{2}{|c|}{$v_{\mathrm{t}}$} & \multirow[b]{2}{*}{$\begin{array}{l}\text { Relative } \\
\text { Error }(\%)\end{array}$} & \multicolumn{2}{|c|}{ TI } & \multirow[b]{2}{*}{$\begin{array}{l}\text { Relative } \\
\text { Error (\%) }\end{array}$} \\
\hline & $\begin{array}{l}\text { Calculated } \\
\text { Value }\end{array}$ & $\begin{array}{l}\text { Measured } \\
\text { Value }\end{array}$ & & $\begin{array}{l}\text { Calculated } \\
\text { Value }\end{array}$ & $\begin{array}{l}\text { Measured } \\
\text { Value }\end{array}$ & & $\begin{array}{l}\text { Calculated } \\
\text { Value }\end{array}$ & $\begin{array}{l}\text { Measured } \\
\text { Value }\end{array}$ & \\
\hline $\mathrm{RC}$ & 21.83 & 22.75 & -4.00 & 0.219 & 0.220 & -0.60 & 0.259 & 0.211 & 22.77 \\
\hline RS-1 & 19.70 & 18.60 & 5.87 & 0.208 & 0.204 & 1.85 & 0.315 & 0.294 & 7.13 \\
\hline RS-2 & 17.35 & 14.87 & 16.67 & 0.197 & 0.182 & 8.14 & 0.464 & 0.452 & 2.68 \\
\hline RS-3 & 15.46 & 15.32 & 0.95 & 0.186 & 0.195 & -4.66 & 0.571 & 0.647 & -11.71 \\
\hline RP-1 & 21.04 & 24.07 & -12.58 & 0.209 & 0.219 & -4.30 & 0.302 & 0.265 & 13.86 \\
\hline RP-2 & 21.39 & 18.45 & 15.96 & 0.200 & 0.201 & -0.29 & 0.359 & 0.329 & 9.03 \\
\hline RP-3 & 20.17 & 20.87 & -3.32 & 0.191 & 0.187 & 2.28 & 0.535 & 0.580 & -7.74 \\
\hline RSP-1 & 17.86 & 16.98 & 5.16 & 0.182 & 0.179 & 1.52 & 0.531 & 0.566 & -6.09 \\
\hline RSP-2 & 16.93 & 18.57 & -8.83 & 0.180 & 0.187 & -3.53 & 0.967 & 0.948 & 2.00 \\
\hline RSP-3 & 14.60 & 15.99 & -8.70 & 0.178 & 0.177 & 0.67 & 0.978 & 0.962 & 1.69 \\
\hline
\end{tabular}


Considering the discrete nature of the concrete, except for individual groups where the relative errors between the calculated and measured values exceeded $20 \%$, the relative errors between the calculated values and the measured values were relatively small. Thus, Equations (6)-(8) can accurately calculate the elastic modulus, the Poisson's ratio, and the uniaxial compression toughness of steel-polyvinyl alcohol fibre-reinforced recycled concrete.

\section{Stress-Strain Curve Model}

Based on the concrete segmentation curve equation proposed by Guo [22], this study proposed the uniaxial compressive stress-strain curve equation for hybrid fibre-reinforced recycled concrete, which is expressed as Equations (9) and (10).

$$
\begin{aligned}
& \left\{\begin{array}{l}
y=\sigma / f_{c} \\
x=\varepsilon / \varepsilon_{0} \\
y=a x+(3-2 a) x^{2}+(a-2) x^{3}(0 \leq x \leq 1)
\end{array}\right. \\
& \quad y=\frac{x}{b(x-1)^{2}+x^{c}}(x \geq 1)
\end{aligned}
$$

where $\sigma$ and $\varepsilon$ are the uniaxial compressive stress and the uniaxial compressive strain, respectively. $f_{c}$ and $\varepsilon_{0}$ are the peak uniaxial compressive stress and the peak strain, respectively. $a$ is the parameter controlling the shape of the rising section and represents the ratio of the initial elastic modulus of the concrete to the peak cutline modulus. $b$ and $c$ are parameters controlling the shape of the falling section.

The multi-parameter least squares fitting method was used to obtain the following Equation (11) for the three parameters to be determined.

$$
\left\{\begin{array}{l}
a=\frac{5.965+1.443\left(\lambda_{s f}+\lambda_{p f}\right)^{0.621}}{-11.056 \lambda_{s f}^{1.154} \lambda_{p f}^{-0.075}+0.703 f_{c}^{0.933}} \\
b=\frac{56.962-62.085 \lambda_{s f}\left(\lambda_{s f}+\lambda_{p f}\right)^{-0.035}-1.7 \lambda_{p f}\left(\lambda_{s f}+\lambda_{p f}\right)^{1.363}}{0.784+0.332 \lambda_{s f} f^{10.31}+0.048\left(f_{c}-40.76\right)^{2.213}} \\
c \frac{-31.183+487.154 \lambda_{s f}\left(\lambda_{s f}+\lambda_{p f}\right)^{-0.313}-\left(1.094 \lambda_{p f}+38.3667 \lambda_{s f}\right)\left(\lambda_{p f}-1.26\right)\left(\lambda_{p f}-2.53\right)}{0.00011 *\left(f_{c}-17.315\right)^{4.137}}
\end{array}\right.
$$

In order to verify the accuracy of the stress-strain curve equation and parameter calculation, the measured results of selected specimens were compared with the calculation results, as shown in Figure 18. The results show that the three-parameter curve model proposed in this study can accurately calculate the uniaxial compressive stress-strain curve of steel-polyvinyl alcohol fibre recycled reinforced concrete. 


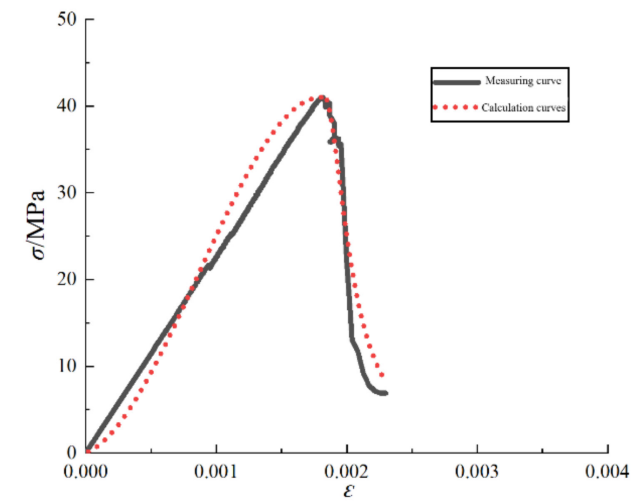

(a) $\mathrm{RC}$

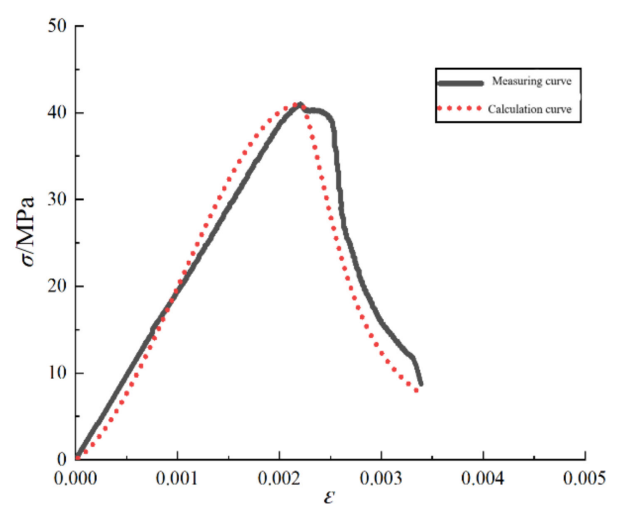

(c) RP-3

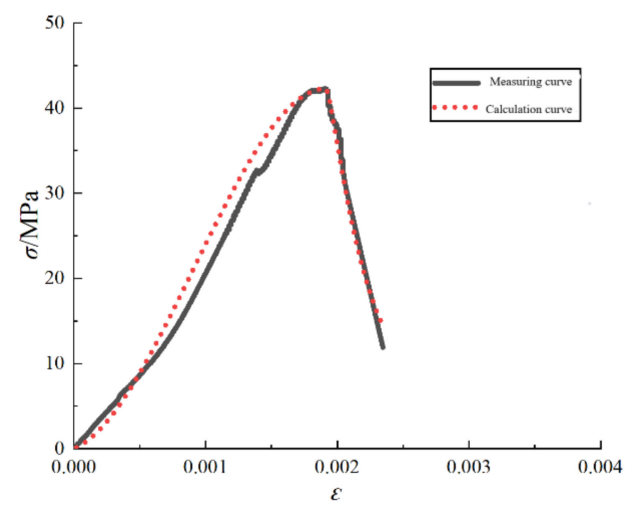

(b) RS-1

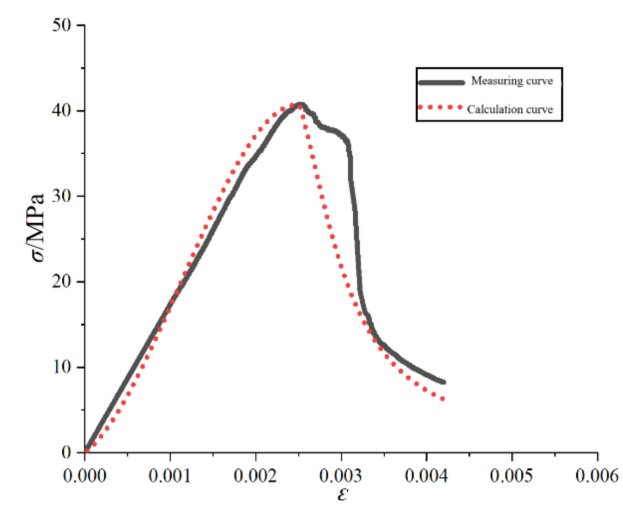

(d) RSP-1

Figure 18. The comparison of stress-strain measuring curve and calculation curve.

\section{Conclusions}

In this study, the mechanical properties of fibre-reinforced recycled concrete were tested. The effect of steel fibre and polyvinyl alcohol fibre on the mechanical properties of recycled concrete was investigated, and the influence of different volume contents of steel fibre or polyvinyl alcohol fibre on the compressive strength, the flexural strength, the elastic modulus, the Poisson's ratio, and the uniaxial compression toughness of the recycled concrete were discussed. Then, a comparison was made between the experimental results and predictions obtained from the mechanical strength model proposed in this study. Finally, a multiple regression analysis of the uniaxial compression stress-strain curve of fibre-reinforced recycled concrete was carried out to establish the equation of the stress-strain curve associated with the fibre characteristic value. The conclusions of this study are as follows:

1. After polyvinyl alcohol fibre was added, the cube compressive strength of recycled concrete decreased by 6.5-14.1\%, while when the polyvinyl alcohol fibre volume content was $0.2 \%$, the flexural strength increased by $47.9 \%$. The brittleness of recycled concrete was improved obviously after mixing polyvinyl alcohol fibre. A single admixture of steel fibre enhanced the recycled concrete cube compressive strength and the flexural strength.

2. After two types of fibre were added, the cube compressive strength of recycled concrete was reduced compared with the non-fibre, but the flexural strength was improved significantly compared with single admixture fibre, especially when steel fibre and polyvinyl alcohol fibre were mixed at $1.0 \%$ and $0.2 \%$ by volume percentage, respectively.

3. The uniaxial compressive strength and the deformation capacity of the recycled concrete were enhanced by incorporating steel fibre or polyvinyl alcohol fibre. The 
deformation performance of the recycled concrete was significantly improved by mixing hybrid fibre compared with single admixture fibre.

4. The incorporation of steel fibre or polyvinyl alcohol fibre reduced the elastic modulus and the Poisson's ratio of recycled concrete but improved the uniaxial compressive toughness. In order to obtain better reinforcement and a better toughening effect, $0.2 \%$ by volume of polyvinyl alcohol fibre and $1.0 \%$ by volume of steel fibre were recommend to be mixed into recycled concrete. In this study, the formula for calculating the elastic modulus, the Poisson's ratio, and the uniaxial compressive toughness of recycled concrete with a calculation accuracy of more than $80 \%$ was proposed.

5. The uniaxial compressive stress-strain curve for each test group was analysed and fitted, then the equation for the uniaxial compressive stress-strain curve associated with the steel-polyvinyl alcohol fibre characteristic value was proposed, which was more complex. However, the calculated curve achieved a high match with the measured curve.

Author Contributions: Conceptualization, H.N., J.L. and L.W.; performed the experiments, L.W. and J.J.; writing - original draft preparation, H.N. and L.W.; editing, J.L. and L.W. All authors have read and agreed to the published version of the manuscript.

Funding: The authors gratefully acknowledge the financial support of the National Natural Science Foundation of China (Project No. U1904188), the Natural Science Foundation of Henan Province (182300410247), the Zhejiang basic public welfare research program (LGF19E080014), and the Huzhou Key Laboratory of Green Building Technology, Huzhou, Zhejiang, China.

Data Availability Statement: The data are presented in the text.

Conflicts of Interest: The authors have declared that no competing interest exist.

\section{References}

1. Banthia, N.; Gupta, R. Hybrid fiber reinforced concrete (HyFRC): Fiber synergy in high strength matrices. Mat. Struct. 2004, 37, 707-716. [CrossRef]

2. Qian, C.X.; Stroeven, P. Development of Hybrid Polypropylene-steel Fibre-reinforced Concrete. Cem. Concr. Res. 2000, 30, 63-69. [CrossRef]

3. Li, Y.F.; Yang, J.H.; Ding, P.; Zhao, H.B. Study on mechanical properties of hybrid fiber reinforced concrete. Com. Sci. Eng. 2013, 2, 60-64. (In Chinese)

4. Aziminezhad, M.; Mardi, S.; Hajikarimi, P.; Nejad, F.M.; Gandomi, A.H. Loading rate effect on fracture behavior of fiber reinforced high strength concrete using a semi-circular bending test. Constr. Build. Mater. 2020, 240, 1-15. [CrossRef]

5. Vishaul, K.; Manikandaprabhu, S.; Radhakrishnan, R. Structural behavior of hybrid fiber reinforced concrete-An experimental study. Mater. Today Proc. 2021, 39, 818-822. [CrossRef]

6. Tam, V.W.Y.; Gao, X.F.; Tam, C.M.; Ng, K.M. Physio-chemical reactions in recycle aggregate concrete. J. Hazard. Mater. 2009, 163, 823-828. [CrossRef]

7. Sidorova, A.; Vazquez-Ramonich, E.; Barra-Bizinotto, M.; Roa-Rovira, J.J.; Jimenez-Pique, E. Study of the recycled aggregates nature's influence on the aggregate-cement paste interface and ITZ. Constr. Build. Mater. 2014, 68, 677-684. [CrossRef]

8. Çakır, Ö. Experimental analysis of properties of recycled coarse aggregate (RCA) concrete with mineral additives. Constr. Build. Mater. 2014, 68, 17-25. [CrossRef]

9. Folino, P.; Xargay, H. Recycled aggregate concrete-Mechanical behavior under uniaxial and triaxial compression. Constr. Build. Mater. 2014, 56, 21-31. [CrossRef]

10. Silva, R.V.; Brito, J.D.; Dhir, R.K. Establishing a relationship between modulus of elasticity and compressive strength of recycled aggregate concrete. J. Clean. Prod. 2016, 112, 2171-2186. [CrossRef]

11. Chen, W.; Jin, R.Y.; Xu, Y.D.; Wanatowski, D.; Li, B.; Yan, L.B.; Pan, Z.H.; Yang, Y. Adopting recycled aggregates as sustainable construction materials: A review of the scientific literature. Constr. Build. Mater. 2019, 218, 483-496. [CrossRef]

12. Xiao, J.Z.; Li, W.G.; Fan, Y.H.; Huang, X. An overview of study on recycled aggregate concrete in China (1996-2011). Constr. Build. Mater. 2012, 31, 364-383. [CrossRef]

13. Zhou, C.H.; Chen, Z.P. Mechanical properties of recycled concrete made with different types of coarse aggregate. Constr. Build. Mater. 2017, 134, 497-506. [CrossRef]

14. Gao, D.Y.; Lou, Z.H.; Wang, Z.Q. Experimental research on the compressive strength of steel fiber recycled concrete. J. Zhengzhou Univ. (Eng. Sci.) 2007, 28, 5-10. (In Chinese)

15. Carneiro, J.A.; Lima, P.R.L.; Leite, M.B.; Filho, R.D.T. Compressive stress-strain behavior of steel fiber reinforced-recycled aggregate concrete. Cem. Concr. Compos. 2014, 46, 65-72. [CrossRef] 
16. Gao, D.Y.; Zhang, L.J. Flexural performance and evaluation method of steel fiber reinforced recycled coarse aggregate concrete. Constr. Build. Mater. 2018, 159, 126-136. [CrossRef]

17. Simões, T.; Octávio, C.; Valença, J.; Costa, H.; Dias-da-Costa, D.; Júlio, E. Influence of concrete strength and steel fibre geometry on the fibre/matrix interface. Compos. B. Eng. 2017, 122, 156-164. [CrossRef]

18. Li, H.D.; Xu, S.L. Research on flexural properties sand flexural toughness evaluation method of ultra-high toughness cementitious composites. China Civ. Eng. J. 2010, 3, 32-39. (In Chinese)

19. Sagar, B.; Sivakumar, M.V.N. Compressive properties and analytical modelling for stress-strain curves of polyvinyl alcohol fiber reinforced concrete. Constr. Build. Mater. 2021, 291, 123192. [CrossRef]

20. Yuan, C.F.; Li, S. Review of fiber reinforced recycled aggregate concrete. Concrete 2018, 9, 31-39. (In Chinese)

21. Ahmadi, M.; Farzin, S.; Hassani, A.; Motamedi, M. Mechanical properties of the concrete containing recycled fibers and aggregates. Constr. Build. Mater. 2017, 144, 392-398. [CrossRef]

22. Guo, Z.H. Strength and Constitutive Relations of Concrete: Principles and applications; China Architecture and Architecture Press: Beijing, China, 2004. (In Chinese)

23. GB/T 25177-2010. Ministry of Housing and Urban-Rural Development of the People's Republic of China. Standard for Using Recycled Coarse Aggregate for Concrete; China Architecture and Building Press: Beijing, China, 2010. (In Chinese)

24. CECS 13:2009. Dalian University of Technology. Standard for Test Method of Fiber Reinforced Concrete; China Planning Press: Beijing, China, 2010. (In Chinese)

25. GB/T 50081-2019. Ministry of Housing and Urban-Rural Development of the People's Republic of China. Standard for Test Method of Physical and Mechanical Properties of Concrete; China Architecture and Building Press: Beijing, China, 2019. (In Chinese)

26. Zhou, J.; Pan, J.; Leung, C.K.Y. Mechanical behavior of fiber-reinforced engineered cementitious composites in uniaxial compression. J. Mater. Civil. Eng. 2015, 27, 401-411. [CrossRef]

27. Guo, Z.H.; Zhang, X.Q.; Zhang, D.C.; Wang, R.Q. Experimental study on complete stress-strain curve of concrete. J. Build. Struct. 1982, 1, 1-12. (In Chinese) 